\title{
MOBILIZAÇÃO E GOVERNANÇA DO CONSELHO GESTOR: O CASO DO MOSAICO CENTRAL FLUMINENSE
}

\author{
Francisco Pontes de Miranda Ferreira ${ }^{1}$
}

\section{Resumo}

A organização da sociedade civil é essencial na busca de transformações sociais. $O$ poder público não deve e não tem a capacidade de promover mudanças estruturais de forma isolada, nem o mercado pode ser absoluto. A maior participação da sociedade produz transformações mais eficazes. A estratégia mais importante para a conservação da Mata Atlântica é a integração das comunidades do entorno das Unidades de Conservação e o incremento do Uso Público, fatores que dependem de um Conselho Gestor participativo e eficiente e um dinâmico sistema de comunicação. O tema do presente artigo é o Mosaico Central Fluminense, cujas ações vêm avançando muito nos últimos anos, principalmente com a instalação do Escritório Técnico que promove um sistema de comunicação e oficinas de Planejamento Estratégico que propõem um modelo de território para os próximos dez anos.

Palavras Chave: Gestão participativa; comunicação ativa; preservação ambiental; riscos e limites.

\begin{abstract}
The organization of civil society is essential in the search for social change. The government should not and does not have the ability to promote structural changes in an isolated form, neither the market can be absolute. Greater participation of society, produces the most effective transformations. The most important strategy for the conservation of the Atlantic Forest is the integration of communities around the protected areas and the increase of public use, factors that depend on a Council Manager participative and efficient and dynamic communication system. The theme of this article is the Central Mosaic of Rio de Janeiro State, whose shares has been advancing in recent years, especially with the installation of the Technical Office which promotes a system of communication and strategic planning workshops that propose a model of the territory for the next ten years.
\end{abstract}

Keywords: Participatory management; active communications; environmental preservation; risks and limits.

\section{Introdução}

Até o início dos anos 1980, a política de gestão e planejamento do uso do território cabia quase que exclusivamente às autoridades e era definida pelo mercado. Esta política autoritária está sendo substituída por processos cada vez mais participativos onde diversos atores sociais podem e devem envolver-se. Existe, portanto, uma ampliação e uma descentralização das decisões. Os Conselhos Gestores representam uma nova força na definição do uso do território. Hoje, temos no Brasil dois grandes desafios na gestão do território: a gestão participativa e a gestão levando em consideração os fatores naturais como a bacia hidrográfica e seus limites reais de uso e ocupação. Uma das estratégias para a conservação da Mata Atlântica é a integração das comunidades do entorno das Unidades de

\footnotetext{
1 Assessoria de Comunicação e Secretaria Executiva do Mosaico Central Fluminense, Mestre em Sociologia e Antropologia (UFRJ), Bacharel em Jornalismo (PUC-Rio) e Licenciatura em Geografia (UFRJ). E-mail: arcalama@gmail.com e secexecmosaicocentral@gmail.com
} 
Conservação (UCs) e o incremento do uso público. Fatores que dependem diretamente de um atuante Conselho Gestor e de um eficiente sistema de comunicação.

As UCs representam limites ao modelo desenvolvimentista, entretanto, o poder de influência dos seus Conselhos Gestores ainda é muito incipiente no controle do território. A maior ou menor capacidade de governança está condicionada à criação de canais institucionalizados legítimos e eficientes de mobilização e envolvimento na elaboração e implementação de políticas, devendo-se ter muito cuidado com a sua formalização excessiva. O desafio maior é transformar os conselhos em instâncias efetivas de controle social sobre o governo e o mercado.

Além das UCs, a Lei do SNUC ( $N^{\circ} 9.985$ de 18 jul. 2000) previu a formalização de mosaicos, ou seja, "um conjunto de unidades de conservação de categorias diferentes ou não, próximas, justapostas ou sobrepostas, e outras áreas protegidas públicas ou privadas", cuja gestão deve ser feita de maneira conjunta e integrada. A Lei também menciona a necessidade de se considerar os diferentes objetivos de conservação, em função das distintas categorias a que essas unidades podem pertencer (proteção integral e uso sustentável; públicas e privadas).

Acredita-se que a comunicação é o fator principal para o conhecimento e transformação, além de ser essencial para a governança, mobilização dos conselheiros e, principalmente, para promover na sociedade o sentimento de pertencimento ao ambiente natural. Uma sociedade com esse sentimento de pertencimento será a principal aliada das transformações necessárias para a garantia da proteção da natureza e o fortalecimento das UCs que compõem o território de um mosaico.

Neste contexto, o presente artigo tem por finalidade apresentar informações sobre a atuação do Conselho Gestor do Mosaico Central Fluminense, criado em 2006, e com 35 UCs de diversas categorias.

\section{Um debate sobre a mudança de paradigmas}

Uma sociedade evolui à medida que se torna capaz de responder aos desafios históricos provocados pela pobreza, falta de mobilização, injustiças sociais e degradação ambiental. A humanidade e o próprio planeta Terra passam por uma situação de grave crise. Pela primeira vez as ações da humanidade colocam em risco o futuro do planeta. É preciso construir uma nova forma de consciência dentro de uma abordagem sistêmica - os seres vivos, as rochas, os sonhos. Como lembra bem Leonardo Boff, a visão dos astronautas da Terra enfatizou mais ainda a necessidade de entrarmos em um novo paradigma.

De lá não é possível distinguir humanidade, Terra e biosfera. Elas formam uma única, grande e complexa realidade. Temos uma mesma origem e um mesmo destino (BOFF, 2005, p. 17-18).

É urgente a necessidade de transformação do nosso nível de conscientização, das nossas relações com as pessoas e com o universo total.

A atuação e a responsabilidade da sociedade civil organizada têm crescido muito, principalmente em função da redefinição das funções do Estado e o incremento da democracia 
participativa. Trata-se do fortalecimento da sociedade civil como ator político e transformador. O próprio processo desenvolvimentista vem passando por uma importante reavaliação das prioridades e uma conscientização de que os modelos que até hoje dominam na relação sociedade/natureza estão se tornando insustentáveis. Os projetos de desenvolvimento local baseados na sustentabilidade ambiental representam uma oportunidade para a criação de cidadãos competentes, participativos e conscientes da necessidade de preservação dos recursos naturais para as gerações futuras. Estamos passando por uma mudança de paradigmas em que transformações ontológicas tornam-se essenciais.

O grande destaque hoje é a capacidade da técnica e da ciência, em nome do capital, transformar o espaço natural de forma tão radical que coloca em risco a própria natureza. Um dos mais importantes teóricos sobre o espaço social é o filósofo francês Henri Lefebvre autor do grande clássico La Producion de L'Espace. O autor argumenta que o espaço geográfico é um "espaço social" que trata, antes de tudo, de um produto social. Lefebvre destaca que cada sociedade e, portanto, cada modo de produção, produz o seu próprio espaço, a sua própria prática e apropriação. A vida social é composta por uma teia de símbolos e interpretações. $\mathrm{Na}$ modernidade introduzimos a competição e o sistema capitalista que desencadeou muitas transformações sociais.

É urgente e necessário um envolvimento profundo e ampliação do sentido de pertencimento com o ambiente. Harvey (1996) chama esta atitude de "construção do lugar" onde atingimos "o sentido geográfico de pertencimento" (p. 169). Neste processo cria-se um sentido comunitário incluindo o solo, a água, as plantas, os animais, a terra, as pessoas - uma consciência das relações ecológicas que operam no local onde habitamos: ser, portanto, membro ativo de uma comunidade biótica. Fato que influencia diretamente as políticas, as relações sociais e as práticas materiais individuais. Na verdade, todo projeto político e social é também ecológico já que o meio ambiente está presente em tudo. "Toda análise crítica com a natureza é simultaneamente uma análise crítica da sociedade”, argumenta Harvey (1996, p. 174). As transformações, portanto, envolvem, antes de tudo, o campo ontológico em que os seres se autoquestionam e buscam modificar assim a própria sociedade.

É necessário percebermos a natureza e a sociedade como complexidades dinâmicas, privilegiando as relações e as correlações no lugar das estruturas mecanicistas e lineares. A permanente transformação de ideias e ações é realizada através do diálogo, do planejamento e da concretização de novas ações. Torna-se, cada vez mais essencial uma mudança de nossa própria visão da natureza e da sociedade introduzindo os conceitos de probabilidade e irreversibilidade.

A educação e o aumento do acesso e a criação de meios de comunicação democráticos é a forma mais eficaz de diminuir a apatia existente. Utilizaremos, portanto, os argumentos do cientista social alemão Jürgen Habermas (1981), um dos pensadores da Teoria Crítica da Escola de Frankfurt. Muitas regiões do mundo continuam mergulhadas na pobreza e faltam organizações baseadas na comunicação. As mudanças só ocorrem para o bem de uma comunidade quando temos um processo de "Comunicação Ativa" e a comunidade se organiza para ações. O processo de desenvolvimento de meios de comunicação independentes, 
libertários e com objetivos concretos de construir uma sociedade participativa, democrática, justa e com metas concretas a serem conquistadas é o caminho da emancipação possível de vencer a apatia e a pobreza. O objetivo principal é a formação de cidadãos que participam ativa e criticamente dos processos políticos, sociais, econômicos, ambientais. Vencer, com isso, a estrutura fragmentária, desigual e confusa existente na sociedade. Substituir assim o isolamento e a fofoca por participação e integração.

Habermas (1981) defende o desenvolvimento técnico, cultural e institucional da humanidade. Isso, segundo o autor, é alcançado através de pessoas capazes de integrar comunicação com ações. Interesses coletivos devem predominar numa sociedade baseada na comunicação ativa e na convivência saudável. Fato que envolve principalmente o diálogo e a cooperação. No entanto, Habermas não defende a racionalidade instrumental (técnica) do capitalismo competitivo para vencer as barreiras da apatia.

\section{O Mosaico Central Fluminense}

O Mosaico Central Fluminense (MCF) foi criado em 2006 e atualmente possui 35 Unidades de Conservação de diversas categorias. O Conselho é composto pelos chefes das Unidades, um representante da Sociedade Civil para cada Unidade, representantes de instituições de ensino e pesquisa e dos Comitês de Bacia envolvidos.

O MCF conta com áreas protegidas federais como o Parque Nacional da Serra dos Órgãos (PARNASO), as Áreas de Proteção Ambiental de Guapimirim e Petrópolis, a Estação Ecológica da Guanabara e a Reserva Biológica do Tinguá; estaduais como o Parque Estadual dos Três Picos (PETP) e a Reserva Biológica de Araras, e municipais de diversas categorias. O MCF possui vertentes para três bacias hidrográficas: ao Sul para a bacia da baía de Guanabara e Norte para a bacia do rio Paraíba do Sul e um pequeno território de Nova Friburgo e Silva Jardim escoa para a bacia do rio Macaé na direção do Oceano Atlântico Leste do Estado do Rio de Janeiro. Os divisores de água são parte do maciço da Serra dos Órgãos, pertencente à Serra do Mar que corta o Mosaico no sentido Oeste-Leste. O Mosaico possui altitudes que vão desde o nível do mar nos manguezais da baía de Guanabara até mais de 2.000 metros nos campos de altitude do PARNASO e do PETP (Figura 01).

A região do MCF possui uma distribuição de renda extremamente concentrada e grande parte da população com baixo poder aquisitivo. A área rural e florestal vem perdendo território com a chegada de condomínios e a produção agropecuária concentrada em pequenos grupos e com uso extremo de agrotóxicos. A área urbana se estende de forma irregular, ocupando encostas, mananciais e beira de canais fluviais. Instabilidades sociais e ambientais tendem a ser potencializadas pelo adensamento da ocupação. Por outro lado, os movimentos a favor da preservação e do desenvolvimento sustentável são marcantes em toda a região com a criação e ampliação de novas Unidades de Conservação e projetos diversos de saneamento, habitação, destinação e coleta seletiva do lixo, aumento da participação da sociedade civil em comitês e conselhos, sistemas agroflorestais e agricultura orgânica. 


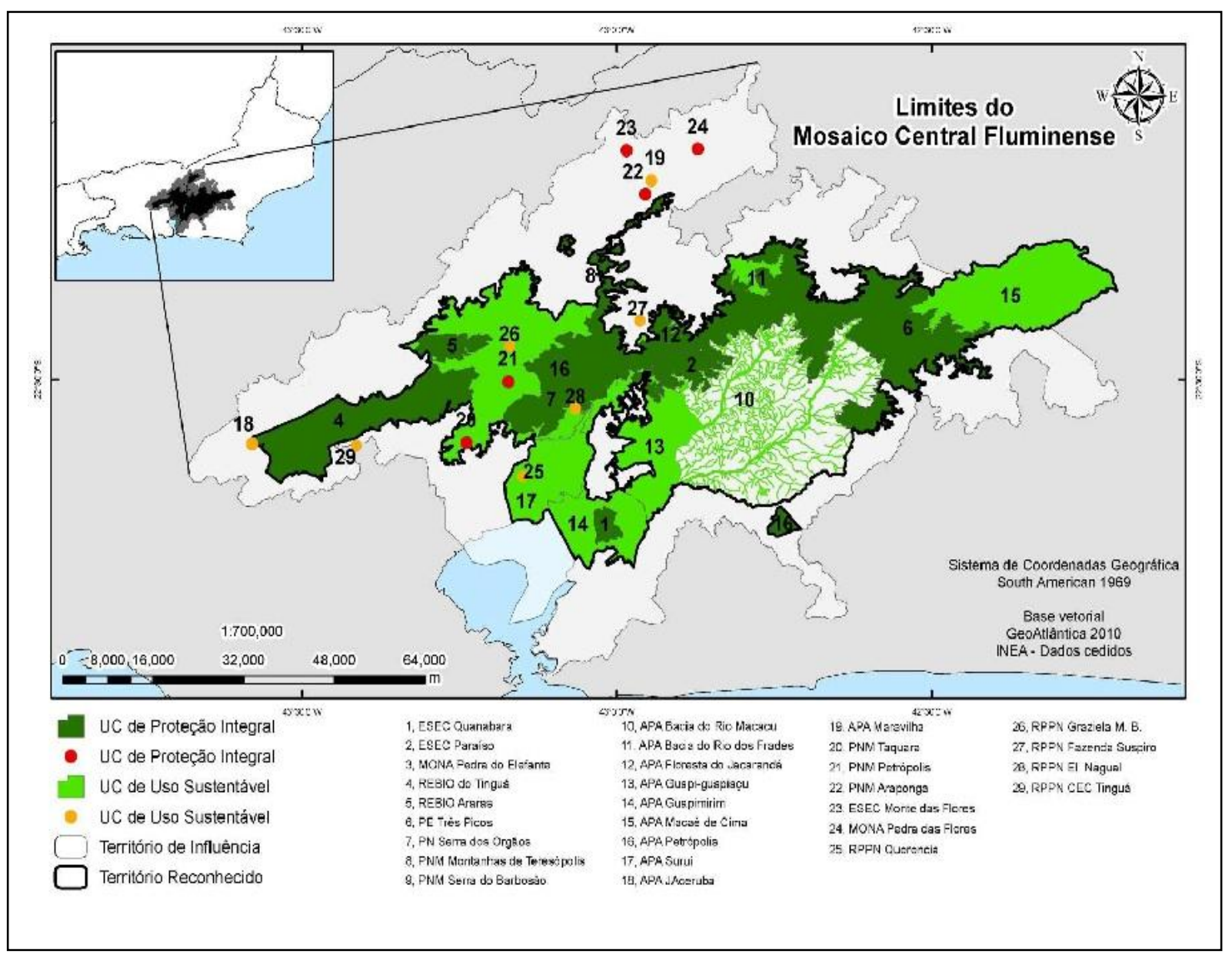

Figura 01. Mosaico Central Fluminense e as Unidades de Conservação Fonte: Conselho do Mosaico Central Fluminense (2010)

O Conselho Gestor conta com um colegiado executivo na direção composto por um membro da instância Federal, um Estadual e um Municipal além de um representante das RPPNs e um da sociedade civil que assume a Secretaria Executiva.

Para realizar que haja mobilização adequada e governança do Conselho Gestor é necessário:

a) conhecer o território;

b) conhecer as regras do território (legislação ambiental, zoneamento, ordenamento, planos de bacia, planos diretores, planos de manejo);

c) formar bancos de dados - participativos e transparentes;

d) sistematizar dados com destaque para as problemáticas e as potencialidades;

e) conhecer os atores: gestores e comunidade;

f) promover a informação/comunicação/rede;

g) elaborar estratégias;

h) resolver problemas e conflitos;

i) aperfeiçoar/capacitar os atores envolvidos;

j) fortalecer o debate. 
O MCF vem avançando muito nestes últimos oito anos. Principalmente com a instalação do Escritório Técnico que promoveu um sistema de comunicação e de diagnóstico e com as oficinas de Planejamento Estratégico que visam estabelecer um modelo de território para os próximos dez anos. As operações de fiscalização integradas também merecem destaque, pois fortalecem a repressão aos crimes ambientais na região com mais efetivo e instrumentos, além de promoverem a integração e o sentido de Mosaico. As ações acima só foram possíveis devido à existência de um conselho participativo e engajado. Como resultado, tem-se um mosaico exemplar e que serve como demonstrativo para outras redes ecológicas.

Através do Escritório Técnico do Conselho Gestor são realizadas diversas visitas técnicas nas UCs e nos interstícios com o objetivo de ter conhecimento profundo dos fatores sociais e ambientais presentes no território. Das visitas técnicas surgem relatórios críticos e um banco de dados que é divulgado através do site, disponibilizado para pesquisadores, sociedade e conselheiros. As pesquisas de campo e o banco de dados foram amplamente utilizados no planejamento estratégico ocorrido em 2010. Os elementos levantados também são utilizados para determinar pautas de discussão para as reuniões do conselho.

O principal canal de articulação do próprio Mosaico é a Comunicação - tanto externa (através do site, boletins, palestras e participações em eventos) quanto interna (convocando os membros do conselho, provocando debates e organizando as reuniões). Através da Comunicação Ativa, ações surgem das demandas e provocam importantes debates. Ações que servem para diminuir o poder do Estado e do mercado e promover a defesa do território em favor da garantia de um ambiente preservado e socialmente justo.

Através do Escritório Técnico foi criado o site www.mosaicocentral.org.br visando ser um canal de informação das UCs que compõem o MCF e que permite divulgar o Mosaico para a população. O site é composto principalmente por notícias que envolvem as Unidades e as atividades do próprio conselho e os profissionais do Mosaico. Existe também espaço para divulgar eventos e editais, publicar atas e outros documentos, expor fotografias das unidades e da região do Mosaico e apresentar parceiros e suas ações. O sistema de comunicação também publicou cinco boletins impressos que foram distribuídos de forma direcionada para ambientalistas, acadêmicos, poder público e participantes de eventos ambientais e culturais da região e do país. O Escritório também atuou na comunicação interna entre conselheiros e profissionais, auxiliando, por exemplo, operações de fiscalização integradas, organizações de eventos como os quatro Encontros de Comunidades do Mosaico e de reuniões das Câmeras Técnicas de Educação Ambiental e Comunicação, Proteção e Pesquisa. O sistema de comunicação teve como relevante instrumento a TV Mosaico com a produção de doze programas temáticos. A TV é acessada pelo site e filmes são estrategicamente distribuídos em escolas, universidades e instituições públicas da região. Os programas também passam em dois canais locais com frequência. As filmagens de alta qualidade são produzidas por equipe da região com recursos internacionais e nacionais através de parceria com o Instituto Estadual do Ambiente (INEA). O MCF ainda conta com um programa de rádio semanal onde são divulgadas as ações e as características do Mosaico e discutidos temas ambientais de relevância para a região. O programa de rádio é veiculado em duas estações da região e pelo site www.brasilruralfm.com.br. 
A equipe do Escritório Técnico realizou visitas técnicas de um, dois ou três dias em todas as Unidades de Conservação. Foram percorridos mais de dez mil quilômetros. Cada visita gerou um relatório na forma de questionário incluindo dados gerais como área, características de preservação, estrutura fundiária e outros detalhes como qualidade e quantidade de equipamentos e recursos humanos e funcionamento de conselho e projetos de pesquisa e educação. Potencialidades e problemáticas das próprias áreas protegidas e do entorno foram descritas. Muitas fotografias foram realizadas e documentos como plano de manejo, regimentos, instrumentos de criação e mapas arquivados. Cada visita técnica gerou também uma reportagem para ser veiculada no site ou boletim. Tem-se, portanto, um importante banco de dados produzido que, além de útil como diagnóstico, serve para direcionar políticas para promoção de melhorias. O conhecimento de campo foi essencial também para o planejamento estratégico, principalmente no mapeamento e zoneamento.

Através de uma oficina inicial do planejamento estratégico, o conselho do Mosaico definiu um objetivo geral para o próprio Mosaico:

Integrar esforços para promover a sustentabilidade e a conservação da diversidade nos ambientes de Mata Atlântica, desde os manguezais até os campos de altitude na Serra do Mar Fluminense, minimizando os efeitos negativos da expansão metropolitana e industrial.

O objetivo destaca características muito próprias do MCF. A primeira é a diversidade provocada pela amplitude de altitude que permite a variação de paisagem da serra até o mar e a outra é a pressão urbana e industrial. O conselho também aprovou uma visão de futuro para os próximos dez anos:

Mosaico como referência de gestão integrada, transparente e participativa, com sustentabilidade política e financeira, UCs estruturadas, instrumentos de gestão implementados (planos de manejo e conselho gestor), equipamentos, pessoal capacitado, e atuando como polo de geração de conhecimento, educação, sensibilização ambiental, com o conceito do mosaico incorporado pelas populações locais. Mosaico considerado em planejamentos regionais, com empreendimentos adequados e redução significativa dos ilícitos ambientais. Práticas sustentáveis, como o uso de energias alternativas, produção orgânica e agro florestal, indústria criativa, ecoturismo e destinação adequada de resíduos consolidados e multiplicados. Áreas degradadas recuperadas com aumento da cobertura vegetal e da conectividade interna e com outros mosaicos.

A definição do objetivo e da visão de futuro foi o ponto de partida para as oficinas de planejamento que tiveram coordenação das organizações ambientalistas Conservação Internacional Brasil e Valor Natural. Foram contratados consultores de socioeconomia que trabalharam com dados existentes e uma profissional de Sistema de Informação Geográfica (SIG). Uma equipe maior composta pela coordenação, consultores contratados e por profissionais das Unidades de Conservação e de Organizações Não Governamentais (sendo alguns membros do conselho) se reuniu várias vezes e o conselho participou de duas oficinas de três dias de trabalho cada. Surgiu um zoneamento para o Mosaico em que o território foi dividido em zona de baixa intervenção composta principalmente por unidades de proteção 
integral; zona de média intervenção com remanescentes importantes para a conectividade e muito bem preservados e áreas ainda com baixo impacto antrópico e zona de alta intervenção onde a ocupação urbana e industrial encontra-se em estágio avançado. Além disso, foram mapeadas as zonas de conflitos marcantes entre atividades antrópicas e preservação ambiental. Um mapa com um cenário provável de expansão urbana e industrial foi também gerado.

Grupos de cada região do Mosaico participaram da elaboração dos documentos e elegeram potencialidades e problemáticas. Definiram também as prioridades para promover melhorias socioambientais. A oficina final definiu as principais políticas para o território do Mosaico como, por exemplo, a recomendação de projetos de saneamento básico para as zonas de alta intervenção, implantação de agricultura orgânica e sistemas agro florestais para as zonas de média intervenção. $\mathrm{O}$ grupo também definiu benefícios diretos para as UCs como a melhoria da estrutura física e dos recursos humanos. A oficina final teve apoio de um profissional especializado em planejamento da Escola Latino-Americana de Áreas Protegidas, Stanley Arguedas Mora. O relatório final do planejamento estratégico se encontra no site do Mosaico e foi distribuído para todas as áreas protegidas.

\section{Atuação do Conselho Gestor}

Os Conselhos Gestores podem se tornar capazes de influenciar diretamente as políticas do uso do território, a favor da sociedade e da proteção da natureza. O Conselho do MCF ainda tem pouca influência nas políticas territoriais, mas pode ser considerada uma experiência positiva para alcançar esse objetivo num futuro próximo.

Conselhos Gestores eficientes dependem de sistemas de comunicação eficazes e dinâmicos. O principal e mais eficiente canal de articulação entre diversos atores sociais deve ser a Comunicação Ativa - onde ações surgem das demandas e provocam importantes debates. Ações que servem para diminuir o poder do Estado e do Mercado e promover a defesa do território em favor da garantia de um ambiente preservado e socialmente justo. A Comunicação Ativa se torna o fator principal de conhecimento e transformação. Essencial para a governança e mobilização dos conselheiros e principalmente para promover na sociedade o pertencimento ao ambiente natural. Só uma sociedade com esse sentimento de pertencimento poderá garantir a proteção da natureza e o fortalecimento das UCs que compõem o território do MCF. Sociedade consciente e conselhos eficientes são as únicas forças capazes de derrubar a lógica do mercado e das políticas centralizadas do Estado.

\section{Considerações Finais}

A mais importante estratégia para a conservação da Mata Atlântica é a integração das comunidades do entorno das Unidades de Conservação e o incremento do uso público. Fatores que dependem de um Conselho Gestor engajado e participativo e de um eficiente e dinâmico sistema de comunicação.

Sensibilizar e mobilizar a comunidade e cada indivíduo é uma estratégia que exige, antes de tudo, compreensão e reflexão. Como extrair ordem do caos? Hoje esta pergunta exige 
um novo diálogo da sociedade com a natureza. A civilização da fábrica espalhou-se, com suas máquinas, com as obras de engenharia, com a indústria do aço, do petróleo e do automóvel. $\mathrm{O}$ universo inteiro parecia funcionar de acordo com a dinâmica da máquina.

Os cientistas hoje tentam provar que a capacidade predatória do homem está se aproximando de um limite e que alguma nova ordem deve surgir do caos. Os cálculos são possíveis a partir do reconhecimento atual de que os recursos úteis são limitados (a capacidade do meio ambiente -K- através da equação logística da ecologia) (PRIGOGINE, 1984: 192). Para que a ordem surja do caos é necessário um caráter reflexivo (como o efeito do espelho).

A vida é fruto da complexidade e do caos. A organização da sociedade civil é essencial na busca de transformações sociais importantes. Estamos convencidos que o poder público não deve e não tem a capacidade de promover mudanças estruturais de forma isolada. Nem o mercado pode ser absoluto. Quanto mais participativa a sociedade, mais fortes e eficazes vão ser as transformações a favor da melhoria da qualidade de vida da população. No entanto, as instituições da sociedade civil organizada precisam investir mais. O objetivo é buscar avanços sociais e não apenas a eficiência econômica baseada no lucro. Através da linguagem (comunicação) as ações ganham um sentido, visando vencer a miséria, a violência, as desigualdades e o isolamento.

Temos que, urgentemente, transformar nossas consciências, nossas relações com as pessoas e com o universo total. Temos que ir além de nossos "mundinhos" individuais e imediatos e transcender para uma visão Gaia - uma nova forma de consciência que inclui tudo - os seres vivos, as rochas, os sonhos e tudo mais como um único organismo complexo e interligado. Como ressaltou Boff (2009): “o ser humano é um projeto infinito”.

\section{Referências bibliográficas}

ALLEN, P. Cities and Regions as Self-Organizing Systems: Models of Complexity. Amsterdam: Gordon and Breach Science Publishers, 1997.

BOFF, L. Tempo de Transcendência: o ser humano como um projeto infinito. Petrópolis: Vozes, 2009.

. Hospitalidade: virtudes para um outro mundo possível. Petrópolis: Vozes, 2005.

CONSELHO DO MOSAICO CENTRAL FLUMINENSE. Planejamento Estratégico do Mosaico Central Fluminense, 2010. Disponível em: <

http://www.mosaicocentral.org.br/pesquisas-e-projetos/305-planejamento-estrategico-domosaico-central-fluminense $>$.

HABERMAS, J. The Theory of Communicative Action. Cambridge: Polity Press, 1981.

HARVEY, D. Justice, Nature \& the Geography of Difference. Oxford: Blackwell, 1996.

LEFEBVRE, H. The Production of Space. Oxford: Blackwell, 2001.

PRIGOGINE, I. Order out of Chaos. London: Bantam Books, 1984. 